\title{
QUE DIZ A RELAÇÃO VIDA E OBRA? - O GOETHE, DE W. BENJAMIN, O NIETZSCHE, DE M. V. DE MELLO, E OUTROS
}

David Barroso

\section{Resumo:}

A questão titular é a investigação da relação vida (autor) e obra. Pelas abordagens de Walter Benjamin, no ensaio Goethe, e de Mário Vieira de Mello, na obra Nietzsche: o Sócrates de nossos tempos, compreendemos qual diferencial existe nesta relação. E pelo diferencial pensamos uma tipificação para o "homem" autor.

Palavras-chave: Experiência. Conflito. Interpretação. Resolução.

\section{WHAT DOES THE RELATIONSHIP BETWEEN LIFE AND WORK MEANS? - THE GOETHE, FROM W. BENJAMIN, THE NIETZSCHE, FROM M. V. DE MELLO, AND OTHERS}

\begin{abstract}
:
The titular question is the investigation of relation life (author) and work. Through the approaches by Walter Benjamin, in essay Goethe, and by Mário Vieira de Mello, in work Nietzsche: o Sócrates de nossos tempos, comprehend what differential there is in the relation life and work. Think through differential one typing "man" author.
\end{abstract}

Keywords: Experience. Conflict. Interpretation. Resolution. 
É sempre difícil decidir se a irresolução torna o homem mais infeliz que desprezível; de igual modo, se é mais inconveniente tomar um mau partido que não tomar nenhum.

Os jovens, por causa das paixões que os ditraem, suportam melhor a solidão que os velhos. Caracteres. La Bruyère.
O grande homem é como a águia; quanto mais se eleva, menos é visível, e é punido, por sua grandeza, com a solidão da alma.

Uma forte resolução transforma imediatamente a mais extrema desgraça em um estado suportável. Do amor. Stendhal.

$\mathrm{Na}$ época considerada Grécia clássica, o discurso filosófico (oral e escrito) era naturalmente relacionado a um modo de vida ${ }^{1}$. Apesar das históricas significações do que seja a noção de filosofia, ou mesmo da de discurso, as grandes obras talvez ainda possuam alguma ligação com a vida de seus autores, e vice-versa. A investigação da relação vida e obra enobrece o discurso do autor com a vida (bios), e sua vida com o discurso (logos). Escrito a suor e sangue, o discurso serve como referencial da vida do autor. Essa investigação traz consigo consequências metodológicas. Uma é o rompimento com a autossuficiência e exclusividade do tempo lógico (na gênese) das teses, pertencentes à estrutura da obra, no caso estruturalismo. Outra, o encontro dos nódulos no substrato vital da gênese das teses, a partir do estudo da biografia, epistolário e fragmentos póstumos. Outra ainda por gerar uma escala de perspectivas metodológicas.

Nesta escala, quando o foco da investigação incide sobre a vida, origina-se um estudo biográfico e, quando a atenção se volta à obra, é o método estruturalista que sanciona as regras $^{2}$. Quando o objetivo de estudo é o autor ou o "homem", por meio das obras, ocorre uma pesquisa historiográfica das fontes de estudo ${ }^{3}$ ou uma "psicologia de casos"4 e, quando a

Esse é o modo que Pierre Hadot compreende a filosofia antiga dos gregos: "o discurso filosófico deve ser compreendido na perspectiva do modo de vida no qual ele é ao mesmo tempo o meio e a expressão e, em consequência, que a filosofia é, antes de tudo, uma maneira de viver, mas está estreitamente vinculada ao discurso filosófico" (HADOT. O que é filosofia antiga?, p. 18).

2 Victor Goldschmidt fala que "o método se encontra em ato nos próprios movimentos do pensamento filosófico, e a principal tarefa do intérprete é restituir a unidade indissolúvel dêste pensamento que inventa teses, praticando um método. [...] Para compreender uma doutrina, não é suficiente não separar a léxis da crença, a regra, de sua prática; é preciso, após o autor, refazer os movimentos concretos, aplicando as regras e chegando a resultados que, não por causa de seu conteúdo material, mas em razão dêsses movimentos, se pretendem verdadeiros. Ora, esses movimentos se apresentam na obra escrita" (GOLDSCHMIDT. A religião de Platão, p. 141-142).f

3 A pesquisa historiográfica das fontes é mais discutida em autores que se utilizam de argumentos subterrâneos, exigindo por parte dos estudiosos uma revisão de suas pesquisas. Um desses é Nietzsche. Rogério Lopes escreve sobre essa questão: "a necessidade de um estudo das fontes se impõe apenas para aqueles intérpretes que entendem o seu trabalho como um trabalho historiográfico, comprometido com a reconstrução do contexto intelectual do autor como uma precondição para a formulação de juízos de intencionalidade. [...] Mas uma vez adotada esta perspectiva, o objetivo último da pesquisa historiográfica é responder não tanto a perguntas do tipo: o que Nietzsche entendeu pelo conceito tal ou qual, mas a perguntas do tipo: o que Nietzsche pretendeu ao utilizar o conceito tal e qual no contexto x e y" (LOPES. Ler Nietzsche contextualmente: ..., p. 114). Do mesmo modo, Werner Stegmaier pensa sobre a questão metodológica na filosofia de Nietzsche: "É possível perseguir através deles [apontamentos póstumos compilados para a obra Vontade de poder] como Nietzsche desenvolveu e formulou seus pensamentos, e por quais pensamentos e formulações ele se decidiu finalmente, e a partir daí pode-se adquirir importantes modos de interpretação. [...] Desse modo, também [Mazzino] Montinari queria ver utilizado o espólio, que deveria então ser ele 
investigação é sobre a relação vida (autor) e obra, obtem-se uma "psicologia da obra". Podemos compreender então a relação vida e obra por, pelo menos, duas vias: a) A influência que a vida exerce sobre as obras (da vida à obra) e; $b$ ) a influência que as obras exercem sobre a vida (da obra à vida).

O "homem" por detrás do autor é o centro de gravidade. O ensaio biográfico Goethe, elaborado por Walter Benjamin, e a obra Nietzsche: o Sócrates de nossos tempos, de Mário Vieira de Mello, compõem exemplos daquelas duas vias da relação vida e obra. O modo como Benjamin e Mello interpretam respectivamente a relação vida e obra do "homem" Goethe e do "homem" Nietzsche, possibilita-nos pensar algumas características das vias da relação (da vida à obra; da obra à vida), e da psique do autor na relação com o pathos inerente aos seus conflitos interiores. Pretendemos apresentar essa relação vida e obra, enquanto relação do grande autor consigo mesmo, como componente principal da noção de resolução. A resolução é o referencial da vida do autor em sua obra e esta, o grande meio de comunicação.

Walter Benjamin e Mário Vieira de Mello abordam a relação de Goethe e Nietzsche com o conjunto de suas obras. O ensaio Goethe, um verbete biográfico ${ }^{5}$; a obra Nietzsche: o Sócrates de nossos tempos, um ensaio com a tese de equivaler Nietzsche a Sócrates devido ao grau de intimidade entre ambos. A partir do modo como expressam o grande autor na relação vida e obra6, observamos que a vida do "homem" Goethe influenciou sua obra e a obra de Nietzsche condicionou sua vida. Em nossa investigação, Goethe é o exemplo da relação "da vida à obra" e Nietzsche o da relação "da obra à vida". Na relação "da vida à obra", a obra

próprio investigado do ponto de vista de suas fontes" (STEGMAIER. Linhas fundamentais ..., p. 300-301).

4 Haviam encontros que reuniam psicanalistas para realizarem um estudo do autor a partir da obra, por diferentes metodologias. Leonardo da Vinci, Dostoiévski, Nietzsche, dentre outros. Maria Rita Kehl nos presenteia com algumas informações: "Por duas vezes, o trabalho de Nietzsche foi discutido nos 'Encontros Psicanalíticos das Quartas Feiras': em abril de 1908 (Genealogia da moral), por sugestão de Hitschimann, e em outubro do mesmo ano, por Häutler. [...] Segundo Assoun, na primeira reunião, a tendência predominante entre os psicnalistas presentes (entre Adler, Federn e Rank) foi a de tentar diagnosticar o autor a partir da obra. A intervenção de Freud teria sido breve e discreta, 'limitando-se a desejar um estudo da influência das impressões infantis sobre as grandes realizações' do filósofo" (KEHL. Ressentimento, p. 154).

5 O ensaio Goethe, escrito por Benjamin entre os anos de 1926 e 1928, era um verbete biográfico para a Grande Enciclopédia Soviética, na qual publicou apenas uma pequena parte. No Brasil, este ensaio foi publicado na obra Documentos de cultura, documentos de barbárie: escritos escolhidos e, posteriormente, em Ensaios reunidos: escritos sobre Goethe. Utilizamos ambas as obras como referência.

6 Compreendemos por "grande autor", servindo-nos da conceituação de Goethe por Benjamin, aquele que "converte seu mundo interior em assunto de interesse público, transforma cabalmente os problemas de seu tempo em problemas de seu mundo empírico e intelectual" (BENJAMIN. Ensaios reunidos ..., Goethe, p. 130). Shakespeare, Pascal, Goethe, Kierkegaard, Nietzsche são exemplos de "grandes autores", sobretudo de "homens" que, valendo-se de Mello, "construíram seu mundo de idéias a partir de experiências que representavam o que podemos chamar de sua base biográfica” (MELLO. Nietzsche: ..., p. 47).

David Barroso - Doutorando pela Universidade Federal do Ceará (UFC), Brasileiro, residente em Fortaleza/CE, E-mail: davidbarrosoo@gmail.com 
sinaliza os conflitos existenciais do autor e, na relação "da obra à vida", a obra expressa uma "vitória" sobre esses conflitos. Como veremos, desde já, a relação "da vida à obra" dá obra à vida e, a relação "da obra à vida" dá vida à obra.

Benjamin inicia seu ensaio com a apresentação do contexto sócio-familiar no qual Goethe nasceu e, do círculo cultural do movimento Sturm und Drung (Tempestade e Ímpeto), dentro do qual nasceu sua produção literária. Na cisão cultural da "burguesia alemã", entre o movimento revolucionário Sturm und Drung e o movimento emancipatório da Aufklärung [Iluminismo], Goethe assimilou o lado negativo de ambos movimentos: "com o Iluminismo colocava-se contra a revolução, com o movimento Tempestade e Ímpeto, contra o Estado"7. Essa cisão ideológica é expressa na obra Götz von Berlichingen (1771), e sua patologia em Die Leiden des Jungen Werthers [Os sofrimentos do jovem Werther] (1774). Obra na qual a "burguesia encontrou o semideus que se sacrifica por ela. Ela se sente redimida, sem estar liberta" _ "desenrola-se o mal du siècle da época em todas as suas nuanças"”.

Benjamin relata que Goethe "não se sentia combatente de vanguarda das classes burguesas, mas sim como seu porta-voz, seu embaixador junto ao feudalismo alemão e junto ao principiado"10. Uma ambiguidade política, pois Goethe "só podia imaginar a cultura burguesa no âmbito de um Estado feudal enobrecido"11. Como tentativa de resolver esse subterrâneo niilismo político (do Estado goetheano), que irrompe em Fausto II, um dilaceramento interior constitui o pano de fundo de suas diversas obras 12, e o refúgio do caráter revolucionário de sua juventude no estudo das ciências e da natureza13. Goethe apreciava mais a aristocracia do Estado feudal que a burguesia do Estado democrático, porém a cultura desta mais que a daquela. Comenta Benjamin: "quanto mais velho, mais adaptava

\footnotetext{
BENJAMIN. Ensaios reunidos ..., Goethe, p. 126.

Ibidem. Goethe, p. 131.

Idem, Documentos de cultura ..., Goethe, p. 44.

10 Idem. Ensaios reunidos ..., Goethe, p. 142.

11 Ibidem. Goethe, p. 143.

12 Dentre as obras, citadas por Benjamin, estão Der Gross-Cophta [O grão-copta], Die Aufgeregten [Os agitadores], Die natürliche Tochte [A filha natural], Hermann und Dorothea, Reineke-Fuchs [A raposa Reineck], Unterhaltungen deutscher Ausgewanderten [Conversas de emigrantes alemães], Iphigenie auf Tauris [Ifigênia].

13 Esse refúgio acentua-se quando Goethe assume o cargo administrativo de conselheiro do Estado, sob a tutela do duque Karl August Sachsen-Weimar. A aceitação do cargo, nos diz Benjamin, foi "o compromisso mais decisivo de toda sua vida", pois, apesar de divergir das diretrizes do Sturm und Drung, garantia "um apoio exterior à sua atuação e eficácia" (BENJAMIN. Ensaios reunidos ..., Goethe, p. 133). No refúgio para as ciências, Goethe elaborou a teoria do Urphänomen [fenômeno primevo]. Benjamin nos diz que "a doutrina do fenômeno primevo como ciência natural era ao mesmo tempo a verdadeira doutrina estética" (Ibidem. Goethe, p. 147). Uma série de estudos foi publicada: A metamorfose das plantas, Meteorologia, Osteologia. Na obra Teoria das cores, Goethe discute sobre o significado do conceito de luz com a Óptica, de Isaac Newton. Discussão retomada pouco mais de 40 anos depois por Arthur Schopenhauer, em Sobre a visão e as cores, de forma polêmica em relação a Goethe.
} 
sua vida a esta ideia política, qualificando-a conscientemente de inqualificável, insuficiente, elevando-a a uma pequena imagem primeva de sua ideia política"14.

Apesar de tudo, forja-se a condição espiritual favorável para o gênio do "homem" Goethe. A noção de formação [Bildung] relacionada com a sociedade moderna, na obra Wilhelm Meisters Lehrjahre [Anos de aprendizado de Wilhelm Meister], e com a pedagogia, contra a política e a teologia, em Wilhelm Meisters Wanderjahre [Os anos de peregrinação de Wilhelm Meister], compõem o enredo do cenário final de Fausto I e II15. A "problemática do Estado" e o "indivíduo isolado" são os principais ingredientes do "drama goetheano". Sua "força propulsora", diz Benjamin, "não é o conflito, mas sim um processo de desdobramento"16 que tende ao sincretismo. Essa relação de Goethe consigo mesmo, expressa na "totalidade da obra literária", sob a persona de Wilhelm Meister e Fausto, "só pode permanecer fragmentária"17, portanto "irônica", mesmo na grande obra Fausto II18.

$\mathrm{O}$ ensaio Goethe apresenta assim um estudo biográfico que enaltece o "homem" Goethe, por transpor seus conflitos interiores, desdobrando-os num sincretismo, para a criação literária. Apresenta-se a nós uma "regra": a obra é influenciada pela vida. Na obra Nietzsche: o Sócrates dos nossos tempos, precisamente o capítulo 2, Mello também enobrece o "homem" Nietzsche, todavia sua "experiência cultural", ainda que paralela à de Goethe, edificou um

14 BENJAMIN. Documentos de cultura ..., Goethe, p. 54.

15 A posição política ambígua de Goethe indica uma tentativa de equilíbrio entre o indivíduo e o mundo social moderno. Georg Lukács expressa melhor esse caráter goetheano: "Tando no aspecto estético quanto histórico-filosófico, Wilhelm Meister situa-se entre esses dois tipos de configuração: seu tema é a reconciliação do indivíduo problemático, guiado pelo ielvivenciado, com a realidade concreta. Essa reconciliação não pode nem deve ser uma acomodação ou uma harmonia existente desde o início. [...] A humanidade, como escopo fundamental deste tipo de configuração, requer um equilíbrio entre atividade e contemplação, entre vontade de intervir no mundo e capacidade perceptiva em relação a ele. Chamou-se essa forma de romance de educação. [...] A ironia, como fator de configuração, assume aqui importância decisiva, pois a princípio não se pode atribuir ou negar sentido a nenhuma estrutura, já que essa sua aptidão ou inaptidão não se manifesta com nitidez desde o início, mas apenas na interação com o indivíduo; essa ambiguidade necessária é reforçada ainda mais pelo fato de que, nas interações isoladas, é impossível assinalar se a adequação ou inadequação das estruturas ao indivíduo é uma vitória ou uma derrota deste último ou mesmo um juízo sobre a estrutura" (LUKÁCS. A teoria do romance ..., p. 138,141,144-145).

16 BENJAMIN. Ensaios reunidos ..., Goethe, p. 141.

17 Ibidem. Goethe, p. 170.

18 Uma descrição precisa é feita por Benjamin sobre Fausto II, obra na qual o espírito prático de Goethe esboça sua compreensão última do mundo e da vida, pois última obra antes do último suspiro: "Quanta apologia e experiência políticas da antiga atividade palaciana de Goethe está presente nesta parte posterior, especialmente nas cenas que transcorrem na corte imperial e nos acampamentos! Se o poeta finalmente precisou concluir com profunda resignação sua atividade ministerial como uma capitulação diante das intrigas de uma cortesã, ele esboça no fim de sua vida uma Alemanha ideal da época do Barroco, na medida em que exagera todas as possibilidades de poder do homem de Estado, mas ao mesmo tempo leva ao grotesco todas as deficiências deste poder. Mercantilismo, Antiguidade e experiência mística da natureza: aperfeiçoamento do Estado através das finanças, da arte através da Antiguidade e da natureza através da experiência são a característica da época que Goethe evoca: o Barroco europeu. E não se trata em última análise de uma necessidade estética discutível, e sim de uma necessidade política íntima dessa obra" (Idem. Documentos de cultura ..., Goethe, p. 60-61). 
"projeto de vida". Este como "uma resolução que se formara anteriormente a qualquer experiência de vida, derivado que era daquilo que só poderia ser definido, no sentido mais rigoroso da expressão, como uma experiência da cultura"19. E esta “devia se realizar através de uma experiência vivida capaz de encarnar a estrutura desse projeto"20.

[Incipit tragoedia -] A relação vida e obra em Nietzsche inicia-se com $O$ nascimento da tragédia (1872), por criar "cria duas novas situações": “O estreitamento de suas relações com Wagner e o esvaziamento de seu prestígio junto às autoridades acadêmicas universitárias"21. A vida de Nietzsche começa a ser afetada por seu discurso, atribuído à sua "doença", como sendo também "questão espiritual", lançando um "gesto" novo. Este, "uma capacidade de autometamorfose até então nunca vista". "Seus livros falam”, diz Mello, "de suas vitórias - e são suas vitórias que determinam sua vida futura, [...] e sobretudo essa própria experiência voltada para o futuro, disposta a agir sobre ele e a determinar sua estrutura"22. Essa "vitória" sobre os conflitos existenciais, fruto da relação de Nietzsche consigo mesmo, gera uma "nova orientação no seu desenvolvimento pessoal”.

Mello, ao equivaler Sócrates (platônico) a Nietzsche, diz que ambos fogem daquela "regra": "Só nelas se veem as obras exercendo uma influência sobre a vida - e a tal ponto, que é sobre os próprios autores dessas obras que as influências começam a se fazer sentir"23. Diz também que a existência da figura histórica de Sócrates é indubitável devido à fidelidade da interpretação platônica, mas que Nietzsche, sem encontrar nenhum "Platão", foi "o primeiro e maior intérprete de si mesmo" - Sócrates e Nietzsche vêm à público interpretados. Para Mello, a autointerpretação de Nietzsche significa "ser personagem, assumir uma possibilidade de vida que permita um novo ângulo de visão da realidade"24, uma outra perspectiva. O

19 MELLO. Op. cit., p. 63.

20 Ibidem. p. 63. Mello não deixa dúvidas ao frisar que o "mundo das ideias (de Nietzsche] tinha uma base biográfica, [mas que] esse mundo de ideias serve também para a existência biográfica de Nietzsche" (Ibidem. p. 48).

21 Ibidem. p. 51.

22 Ibidem. p. 51

23 Ibidem. p. 70. Mello confronta Nietzsche com outros "grandes autores" a partir da relação vida e obra: "Shakespeare, por exemplo, escreveu Hamlet para conjurar o fantasma do regicídio; Goethe escreveu Werther para conjurar a tentação do suicídio; Dostoiévski transferiu para seus romances um excesso de vitalidade que os limites de sua existência física não permitiam encarnar. Nietzsche, pensam então alguns analistas, teria, do mesmo modo, feito da filosofia um instrumento para dar largas a seu temperamento explosivo" (Ibidem. p. 49).

24 Complemento: "Esse intercâmbio entre realidade e interpretação é um fato fundamental nas obras de Sócrates e de Nietzsche. Sem Platão, a realidade de Sócrates jamais nos seria acessível; sem o Nietzsche-intérprete, o Nietzsche real seria para nós um mundo inatingível" (Ibidem. p. 54). A "autointerpretação" de Nietzsche gera consequências ao estudo de sua filosofia: a presença de figuras de linguagem ("máscara", "esotérico e exotérico", "Dioníso e Apolo", "hierarquias de espírito"), o caráter fluido do "eu" (o "si”), uma "psicologia dionisíaca", uma outra noção de formação (de si) sob a égide "torna-te quem tu és", e mais. 
"homem" Nietzsche autointerpreta-se a cada obra novamente. Esta é a experiência da cultura como projeto de vida; "a interpretação da vida como um projeto"25.

A cada nova interpretação de si, uma "vitória" sobre seus conflitos anteriores, uma resolução diferente em seu projeto de vida - outra perspectiva, a nuance da filosofia. Mello diz que "sua psicologia é a mais extraordinária realização de que se tenha notícia na cultura do Ocidente", advinda do "sonho de um ressurgimento de uma cultura trágica, dionisíaca dos gregos, frustrado com a experiência wagneriana"26. E comenta que toda a vida de Nietzsche “foi repentinamente influenciada por um projeto que já exprimia o essencial de sua obra [em O nascimento da tragédia]. [...] A consequência inevitável de um empreendimento a que não pudera se furtar", pois “era preciso morrer para uns para renascer para outros"27 - tal qual Sócrates, o condenado.

\section{II}

Com a apresentação das duas vias da relação vida e obra, a partir das abordagens de Benjamin e Mello, percebemos que, ao ato de criação da obra, Goethe e Nietzsche relacionaram-se com o pathos de seus conflitos de modos diferentes. Conflitos idiossincráticos, singulares, únicos que, apesar de camuflados no "gesto" da escrita ao compor o próprio "estilo", seus combates, esforços e dificuldades são passíveis de interpretações 28. Por conflito, compreendemos tal como Gaston Berger: "sentir a vida como uma consequência de lutas e dar-lhe o sentido particular que nosso caráter lhe confere", que traduz o fato da vida não ser, para ninguém, "um desenrolar sem incidentes, no qual todas as nossas aspirações seriam harmoniosamente satisfeitas"29. Naquelas abordagens, percebemos que a postura do "grande autor" nem sempre é ativa no enfrentamento dos conflitos existenciais. A passividade, seja lá por qual motivo, denota adiar indeterminadamente uma resolução sobre si na tentativa de uma conciliação consigo mesmo. Enquanto a atividade aponta para a experiência da cultura, na qual a "vitória” sobre os conflitos gera um comportamento resoluto

\footnotetext{
Ibidem. p. 66.

Ibidem. p. 61.

Ibidem. p. 71-72.

28 "Estilo" é uma noção com várias perspectivas. Freud realizava encontros psicanalíticos para estudar o "estilo" das obras por meio do estudo da infância do autor (cf. Nota 5). A grafologia moderna estuda a expressão particular de um traço da personalidade, do caráter, de estados fisiopsicológicos pela análise do "estilo" de escrita. Em textos digitais, alguns métodos grafológicos precisam ser adaptados enquanto outros são dispensáveis. A filosofia de Nietzsche contribui bastante com sua "genealogia da moral", ao observar os valores inerentes ao ato (de criação), pela escolha. Com isto, e através de abordagens minimamente aceitas sobre qualquer "grande autor", como as de Benjamin e Mello, conseguimos encontrar diferentes tipos de resolução dos conflitos interiores. Veremos então que até o disfarce é revelador.

29 BERGER. Tratado prático de análise do caráter, p. 64.
}

David Barroso - Doutorando pela Universidade Federal do Ceará (UFC), Brasileiro, residente em Fortaleza/CE, E-mail: $\underline{\text { davidbarrosoo@gmail.com }}$ 
imanente à criação da obra, como projeto de vida.

Compreendemos duas coisas. Primeira: A postura passiva de Goethe frente aos próprios conflitos existenciais, no ato de criação da obra, diz da tentativa de resolução consigo mesmo como uma tentativa de conciliação entre vida e "homem" (autor): a comunhão de seus conflitos em um desdobramento sem desfecho. A obra assim é ela mesma a tentativa de resolução, conciliação. Sua escolha é a não-escolha do enfrentamento, a grande luta adiada. As experiências de vida, decorrentes da escolha, não são experiências da cultura, mas seus conflitos estimulantes ao ato de criação. Como tentativa, a obra é um comunicado confesso ao público e - talvez com sua repercussão cultural -, o meio no qual o autor deseja encontrar algo que ponha um fim às dificuldades de suas experiências. Na relação "da vida à obra", obra está sendo um resultado do laboratório da mente do grande autor e seus conflitos, substrato das experiências de vida.

Segunda: A postura ativa de Nietzsche frente aos próprios conflitos existenciais, no ato de criação de uma obra, diz de uma resolução consigo mesmo enquanto conciliação momentânea entre vida e "homem" (autor) - o bradar vitorioso sobre seus conflitos interiores pela resolução dos conflitos anteriores. A obra assim é ela mesma o dizer da resolução, conciliação. Sua escolha é o enfrentamento, a luta dos vencedores e vencidos. As experiências de vida, decorrentes da escolha, são experiências da cultura e componentes imprescindíveis ao ato de criação. Como resolução, a obra é já uma interpretação do próprio autor e - nas experiências seguintes -, o passo com o qual o autor deseja experimentar outras interpretações para outros e novos conflitos. Na relação "da obra à vida", a obra é o resultado contínuo do laboratório da vida do "grande autor" e seus conflitos, substrato e matéria-prima das experiências da cultura30.

No enfrentamento, a postura ativa em relação ao pathos dos conflitos tende a resolvê-los por meio de uma interpretação. Uma interpretação possível e aceitável, dentre tantas. Ela mesma, a interpretação, é o diferencial. Sendo a interpretação dos conflitos uma interpretação

30 "Experiência de cultura", termo designado por Mello, equivale à expressão "experiência do pensamento", atribuída à filosofia de Nietzsche. Olimpio Pimenta Neto contribui ao dizer-nos da "experiência do pensamento" como "experiência do filósofo", a "filosofia": "Enquanto espírito livre [o filósofo], este não tem prazer na busca de certezas, com todos os efeitos analgésicos que decorrem do seu estabelecimento - pois é certo que quem procura, acha. Enquanto espírito trágico, entende o sofrimento como contrapartida solidária da alegria, e não desdenha de nenhum dos dois. Principalmente: enquanto legislador, define a fidelidade à terra como elemento primordial para uma filosofia afirmativa, que faz da experiência do pensamento nossa melhor chance neste mundo. [...] A experiência do filósofo pode realizar um movimento sem precedente na história a favor da independência, situando sua atividade rente ao coração selvagem da vida. [...] Mas o mais importante, que nunca deve ser negligenciado, é a navegação ela mesma - ou o espírito da aventura mesmo. Porque as respostas, afinal, contam pouco diante das perguntas - e é pela vitalidade destas que se aprecia o alcance da experiência do pensamento, ou, simplesmente, filosofia" (NETO. O que é filosofia?, p. 264, 266). 
que o grande autor faz de si, para uma resolução momentânea das experiências de suas escolhas, a autointerpretação é então a referência que dista o criar(-se) da postura ativa do desdobrar(-se) da passiva. Dista por conseguinte os modos como Goethe e Nietzsche relacionaram-se com seus conflitos, apresentando-nos respectivamente as duas vias da relação vida e obra, sem impedir a manifestação da genialidade de cada um. Mais que isto. Tomando a autointerpretação como referência, pensamos o diferencial na noção de resolução.

III

Uma digressão. Investigamos a relação vida (autor) e obra por duas vias. Uma (da vida à obra), a vida influencia a obra. Apresenta um desdobramento conflituoso sem desfecho que tende ao sincretismo. Lemos que isso advém do caráter "irônico" da postura passiva do "homem" autor na relação com seus conflitos existenciais. Não interessa qual motivo. A autointerpretação não pode ocorrer senão se o "homem" autor escolher o enfrentamento. Não importa qual (auto)interpretação; ela é o diferencial. O que ocorre na outra via (da obra à vida). Nesta, a obra influencia a vida. Apresenta-se como uma resolução momentânea do "homem" autor devido ao caráter agônico da sua postura ativa na relação com seus conflitos. O que interessa é a autointerpretação, a escolha do enfrentamento. O "homem passivo" faz de sua obra uma comunhão de seus próprios conflitos. O "homem ativo" faz de sua obra uma gaia ciência dos seus conflitos oriundos de suas experiências (da cultura). Aquele tem como resolução um comunicado confesso, este a "superação" momentânea. Mas para pensarmos a noção de resolução, isso não é o bastante.

Pensamos primeiro. Uma resolução resulta de um pôr-se frente ao pathos dos conflitos, e encará-lo com coragem, sem querer aniquilá-lo - enfrentamento. É momentânea, porque corresponde a uma ação (ao mesmo tempo, reação) para um contexto próprio e irrepetível, único e singular. A experiência tem seus custos, a resolução seus benefícios. As condições não são totalmente controladas e, não se vive muito mais que um século - no laboratório da vida, precisa-se de vida, tempo é vida. Apesar dos riscos e com os riscos. A autointerpretação gera um background que contribui à formação de si. Da autointerpretação à resolução, uma conciliação momentânea; o período de assimilação no qual o "homem" autor assimila-se a si mesmo - a análise dos dados vitais para a síntese na resolução. Através da ação (do ato de criação de uma obra) gera-se outro contexto. Cada contexto é aberto ainda que coeso, suscetível à intervenções por diferentes ações por todos os lados - devir, o fluxo da vida. A resolução dos conflitos gera uma ação que provoca adiante outros conflitos. Além de que cada 
resolução é uma perspectiva idiossincrática, singular, única para um determinado momento da vida e, principalmente, diz da (auto)interpretação do "homem" (autor). Cada ação, uma (auto)interpretação que traz consigo um tipo de enfrentamento dos conflitos existenciais. Assim sendo, caracterizaremos a resolução por sete modos.

Podemos organizá-los em dois grupos. Em um não há a autointerpretação do "homem" autor, no outro ocorre. No primeiro grupo, já é conhecido por nós o exemplo benjaminiano de Goethe: Da obra como comunicado confesso e, este como tentativa de resolução. Resta-nos outro exemplo a esse grupo. Valeremo-nos da filosofia de Nietzsche ou, como disse Mello, de sua "psicologia". Escreve: "O que toda grande filosofia foi até o momento: a confissão pessoal de seu autor, uma espécie de memórias involuntárias e inadvertidas. [...] E particularmente a sua moral dá um decidido e decisivo testemunho de quem ele é"31. Servindo-nos desta grande filosofia como sendo para nós uma grande obra, vemos que nela o "homem" autor desconhece ou negligencia seus conflitos existenciais, mas que, ao realizar seu discurso, confessa-os involuntariamente. O enfrentamento não se dá, muito menos uma autointerpretação. Neste tipo de resolução, a obra é uma confissão involuntária dos conflitos. Se no comunicado confesso a escolha é a não-escolha, na confissão involuntária a escolha não existe. Sua luta é instintiva (a conservação de si).

No segundo grupo, onde há autointerpretação, já é-nos conhecido o exemplo melloniano de Nietzsche: Da obra como "superação" momentânea e, esta como resolução dos conflitos existenciais. Falta-nos outros exemplos. Valeremo-nos da noção de auto-engano, sugerida por Eduardo Giannetti na obra Auto-engano. "O fulcro do auto-engano", apresenta Giannetti, "reside na capacidade que temos de sentir e de acreditar de boa-fé que somos o que não somos. [...] É a pretensão ilusória e infundada do auto-conhecimento. [...] É preciso que eu minta para mim mesmo e, ainda por cima, acredite na mentira"32. Servindo-nos deste homem auto-enganado como sendo para nós o grande autor, vemos que sua obra mantém uma aparência de "superação", pelo enfrentamento ilusório dos conflitos. Para isto há vários caminhos, mas qual caminho importa-nos?33. Ocorre o enfrentamento, porém a

31 NIETZSCHE. Além do bem e do mal. 6, p. 12-13.

32 GIANNETTI. Auto-engano, p. 106-113,118.

33 Os caminhos que levam o "homem" autor a auto-enganar-se são subjetivos e dependem da "formação de vida" de cada um. Buscar traçá-los é vão agora, cabendo-nos apenas alguns lances: A ingenuidade de si, seja lá por qual motivo, permite inocentemente a formação e fixação de crenças; o autoconvencimento honesto na crença de boa-fé da pia fraus; a "luta instintiva" para a autoconservação do "homem" provoca motivações que o dominam e estendem-se ao comportamento individual, seguidas de "cumplicidade passiva ou colaboracionismo ativo", até tornar-se hábito (a aproximação entre a "confissão involuntária" e o "autoengano") - a leitura equivocada, mas sedutora, dos conflitos interiores gerando no "homem" autor uma 
autointerpretação está enganada, portanto a resolução do "homem" autor só pode ser uma aparente "superação". Auto-enganada, mas não "hipócrita". Se na confissão involuntária a escolha não existe, na aparente "superação" a escolha é uma ilusão. Sua luta é a ilusão do auto-engano (o ocultamento de si).

Ainda no segundo grupo, nosso último exemplo de resolução pela autointerpretação. Valeremo-nos da noção de hipocrisia ensejada pela tese de Gustavo Costa no artigo Hipocrisia, moralidade, caráter. Escreve: "uma coisa é a sua origem enquanto arte do autor; outra é a origem das práticas às quais, posteriormente, o termo hipocrisia foi associado e avaliado: as práticas consideradas amorais ou ainda, imorais"34. Servindo-nos do homem hipócrita como sendo o grande autor, vemos que sua obra possui duas leituras: a) um caráter inventivo que visa a criação artística e a constituição de um ethos; e $b$ ) uma falsidade hipócrita, velada e astuciosa que visa enganar deliberadamente seus crédulos leitores. Não interessa qual motivo, sempre haverá motivos. O enfrentamento é o domínio do manuseio dos dados vitais inerentes aos conflitos existenciais e, a autointerpretação o jogo ponderado da manipulação - moral, amoral ou imoral?. Sua resolução é um "gesto" dissimulativo, uma arte da dissimulação ou uma dissimulação astuciosa. Se na aparente "superação" a escolha é a ilusão do auto-engano, no "gesto" dissimulativo é o proveito próprio, como criação de si ou disfarce de si. Sua luta, a sedução (persuasão) ou a mentira (pia fraus ou engano).

\section{IV}

Finalizaremos sem concluirmos. Sobre a relação vida (autor) e obra, faremos ainda algumas observações pertinentes. (Re)organizaremos então os dois grupos com os (sete) modos que caracterizam a noção de resolução, distinguindo-os pelo tipo de relação que o grande autor tem consigo mesmo. Antes, uma observação. Partimos das abordagens de Benjamin, sobre Goethe, e de Mello, sobre Nietzsche, para pensarmos o diferencial na relação vida e obra. Estabelecido o diferencial como autointerpretação, pensamos algumas variantes

autointerpretação também equivocada. Não contamos neste caso com o "poeta fingidor" nem com o "leitor hipócrita". Giannetti diz que o poeta fingidor "é um artista consumado no looping do auto-engano. [...] Contudo, ele não está sozinho. O leitor hipócrita, irmão de Baudelaire, é sua alma gêmea. Se o ator dramático age e chora sem mentir, o espectador sente e chora sem agir. Um é o negativo fotográfico do outro" (GIANNETTI. Op. cit. p. 131).

34 Complemento: "Nesta [segunda] hipocrisia, enquanto prática da astúcia e da dissimulação, assume o fardo de uma avaliação na qual lhe é conferida o estatuto de 'mãe de todos os vícios', a própria antípoda de um comportamento moral e, sob essa perspectiva, ético" (COSTA. Hipocrisia, moralidade, caráter, p. 115-116). O problema ético-estético, ou ético-poiético, da "criação de si", a partir da noção de hipocrisia, na filosofia de Nietzsche, é discutido com mestria por Costa em sua tese de doutoramento: COSTA, Gustavo Bezerra do Nascimento. Hipocrisia: arte do engano, arte do ator. Um olhar sobre a criação de si em Nietzsche. Tese (Doutorado em Filosofia) - Universidade do Estado do Rio de Janeiro (UERJ). Rio de Janeiro: [s.n.], 2013. 
que agora compõem, junto ao "homem" Goethe e ao "homem" Nietzsche, as duas vias daquela relação (da vida à obra; da obra à vida), por meio de outras teses (do próprio Nietzsche, Giannetti e Costa), poupando-nos assim de aventurarmo-nos noutras abordagens, já ousadas por estes. Com a organização das teses, uma tipificação do "homem" autor diz dos modos pelos quais caracterizamos a noção de resolução.

Uma nota. Compreende-se modo como um aspecto psicológico do "homem" (autor), na relação com seus conflitos existenciais, expresso no ato de criação de uma obra35. O diferencial consiste da autointerpretação que o "homem" autor realiza de si mesmo na relação com seus conflitos existenciais. Um modo equivale-se à presença ou ausência de uma autointerpretação que diz, por certas expressões, do enfrentamento dos conflitos e de sua resolução. Fazer uma investigação da relação vida e obra, tateando alguma ligação entre ambas, não tem nada de novo e parece ser vão, pois já é atestado seu valor científico. Todavia, nos é de grande valia, tanto pela discussão metodológica, como pela compreensão das sombras da palavra, os sentidos das entre-linhas. Uma grande obra não seria se não nos desse nada mais que palavras aladas - tempo é vida que também é existência. Deve ser um clássico, livro de formação, porque ação de um grande autor, mas por que não também, obra de um grande homem36. Assim sendo, percebemos a utilidade prática de uma investigação da relação vida e obra, na qual os modos do aspecto psicológico do "homem" (autor) fornecem uma tipologia. Cada tipo se apresenta, então, como a forma (psicológica) específica do caráter da obra.

O primeiro grupo compreende dois modos em que o "grande autor" não realiza autointerpretação. Por sua postura passiva, não há o enfrentamento dos conflitos existenciais. Numa escala astuciosa: 1) O tipo homem confissor. Sofre pela ignorância de si, desconhecendo ou negligenciando os conflitos. Não há enfrentamento nem autointerpretação e nem, por consequência, resolução. Sua ação em obra expressa uma tendência à conservação

35 Numa perspectiva mais ampla do jeito como compreendemos os modos de resolução (tipos psicológicos do "homem" em relação com seus conflitos), Gaston Berger apresenta: "A vida psicológica, então, não mais se apresenta como formada de qualidades inertes, mais ou menos gerais e hierarquizadas, como o são as noções na árvore de Porfírio. Nela descobrimos um sistema de forças que ora se juntam, ora se combatem, ora se neutralizam" (BERGER. Op. cit. p. 63).

36 Ítalo Calvino diz mais: "Formativas no sentido de que dão uma forma às experiências futuras, fornecendo modelos, recipientes, termos de comparação, esquemas de classificação, escala de valores, paradigmas de beleza" (CALVINO. Por que ler os clássicos, p. 10). La Bruyère diria: "Quando uma leitura eleva o espírito, inspira sentimentos nobres e de coragem, não se deve procurar outra regra para julgar a obra; é bou e feita por mão de mestre" (BRUYÈRE. Caracteres, Das obras do espírito, 31, p. 25). Amplia-se a visão de mundo, contribuindo também à "formação de si", como um modo de (vida) enfrentamento da existência. Para Gaston Berger, um modo de vida determina o "estilo de vida, que está sob a dependência do caráter". Sobre o caráter, diz-nos: "O caráter se apresenta, então, como a forma específica de enfrentar os conflitos, de resolvê-los e, antes de tudo, de equacioná-los, de lhes dar um sentido" (BERGER. Op. cit. p. 64).

David Barroso - Doutorando pela Universidade Federal do Ceará (UFC), Brasileiro, residente em Fortaleza/CE, E-mail: $\underline{\text { davidbarrosoo@gmail.com }}$ 
de si perante à existência. 2) O tipo homem (goetheano) contemplativo. Sofre com o fechamento de si, desdobrando seus conflitos sem negligenciá-los, numa tentativa de comungá-los sem enfrentá-los. - "Irônico". Sua resolução é justamente essa tentativa de resolução. Sua ação em obra expressa o angustiante dilaceramento de si durante a existência.

O segundo grupo compreende cinco modos em que o grande autor, em sua postura ativa, enfrenta seus conflitos existenciais, realizando uma autointerpretação de si. Segue: 3) O tipo homem (nietzscheano) agônico. É permanente o enfrentamento dos conflitos. Na medida do possível, pela autointerpretação, é conhecedor dos próprios conflitos cultivando-se a si mesmo. Sua ação em obra expressa a corajosa conquista de si na existência. 4) O tipo homem auto-engando. É uma ingenuidade de si [Naïf] sua crença em viver uma ilusão autotrófica. Sua autointerpretação autodissimula-se, a dissimulação da dissimulação37. Sua ação em obra expressa uma ingênua dissimulação de si mesmo junto à existência. 5) O tipo homem (hipócrita) artista. Seu enfrentamento é a simulação de si que na autointerpretação encorpora um outro de si. Arte da dissimulação que, conforme se apropria do outro na simulação de si, dissimula o que se tornou. Sua ação em obra expressa a oportuna criação de si durante à existência. 6) O tipo homem (hipócrita) platônico. Seu enfrentamento, uma projeção de si que na autointerpretação mostra-se como máscara. Uma dissimulação astuciosa, pois se vale de uma mentira que visa um objetivo nobre (pia fraus), muitas vezes não só para $\mathrm{si}^{38}$. Sua ação em obra expressa o maquiavélico disfarce de si para a existência. Last but not least. 7) O tipo homem (hipócrita) burlador. Seu enfrentamento é a ficção de si que na autointerpretação mostra-se também como máscara. Uma dissimulação astuciosa, pois se vale de uma mentira para proveito próprio pelo engano do outro, que nem sempre sofre perdas. Sua ação em obra expressa o malandro disfarce de si pela existência.

Por essa tipificação do "homem" autor estende-se uma tipologia psicológica do "homem" em relação com seus conflitos. Como no laboratório da vida não existe experiência

37 Lembramos de Torquato Accetto, quando escreve: "Simula-se aquilo que não é, dissimula-se aquilo que é" (ACCETTO. Da dissimulação honesta, p. 27).

38 Sobre a pia fraus na filosofia de Platão, fala Nietzsche: "Na República (376e), é muito curioso: aqui distingue Platão dois tipos de discurso, os que contêm a verdade e os que mentem; a estes últimos pertencem os mitos. [...] Em 389b também se expressa do mesmo modo, quando diz que as mentiras são úteis ao homem em determinadas circunstâncias e que deve ser permitido aos governantes servirem-se dela para o bem de seus cidadãos" (NIETZSCHE. Escritos sobre retórica, p. 84. Tradução nossa). Para pensarmos, além da pia fraus (cf. nota 33): "O que faz com que um mentiroso nos venda um erro como se fosse verdade? A sua 'razão prática' (- a sua vantagem, falando em termos populares) $\mathrm{O}$ que faz com que a gente se decida entre diferentes possibilidades? A sua razão prática, a sua vantagem... O que faz com que entre diferentes hipóteses se escolha desse ou daquele modo? A vantagem. Que diferença subsiste entre alguém que foi persuadido e alguém ao qual foi mentido? Nenhum, se foi bem mentido. [...] A fiç̧ão, a utilidade, a suposição, a probabilidade, a certeza, a convicção - uma história do pathos interior, em cujos primórdios está a mentira, o seu deus..." (Idem. Fragmentos ..., 14 (159), p. 206). 
pura, já que as condições não são totalmente controladas, também não existe um tipo psicológico puro, nem a obra expressa ação de apenas um tipo "homem" autor. E, por merecimento, o laboratório da mente é o espelho da vida. Pensamos assim a presença do convívio de dois ou mais tipos psicológicos combinados em um mesmo "homem" autor. Um estudo da combinação desses tipos diz respeito ao aprofundamento da investigação da relação vida (autor) e obra porém, à nossa pretensão, está lejos de nosotros - controle do tempo útil, economia de vida. Não queremos uma "psicologia de casos" nem uma caracterologia. Sobremaneira, aproximamo-nos da primeira e equidistamo-nos da segunda, sem procurarmos nenhuma das duas. Por afinidade, todavia, esboçamos o procedimento caracterológico de Berger para entrevermos uma combinação dos tipos psicológicos do "homem" autor.

$\mathrm{Na}$ caracterologia bergeriana, situada "no grau das constantes individuais", o estudo escalona-se desde o discernimento da subestrutura somatopsicológica do indivíduo (o caráter do "homem" permanente) até a análise das superestruturas da personalidade (a individualidade do "homem" variável). O caráter é a base da vida (psicológica) e a personalidade, a síntese dos fatores (fundamentais, complementares, de tendência) com a história pessoal. Da "análise da personalidade" realiza-se uma combinação fatorial (binária e terciária), ansiando por um "sentimento exato da síntese", até obter-se um esquema com oito tipos de caráteres39. Sem ferramentas estatísticas, mas com estudos filosóficos, obtemos sete aspectos psicológicos da relação do "homem" (autor) consigo mesmo, no enfrentamento dos próprios conflitos existenciais, expressa em obra. Se procedessemos semelhante ao método de Berger, combinaríamos os sete tipos entre si, ilustrando-os através das grandes obras. Há várias combinações possíveis que só valerão à medida que houver equivalência real com um grande autor. E esta seria buscada em abordagens tais como a de Benjamin e a de Mello.

Ainda assim, pensamos. A postura ativa do "homem" frente aos seus conflitos existenciais, possui uma variação que diz respeito àquilo que se chama "liberdade". Pela liberdade de escolha, o "homem" afirma o jogo de forças resultantes da atividade do pathos inerente à vida. Prova da interrelação logos-pathos. Escrita a suor e sangue, a grande obra é o referencial da vida do "homem" autor. Em suas linhas e entre-linhas, a efluência daquele jogo

39 Sobre a caracterologia: "Parte-se simplesmente, modestamente, da variedade dos indivíduos, para tentar ver como o seu comportamento, suas representações e seus sentimentos se relacionam uns aos outros. [...] Um dos melhores métodos consiste em estudar, em seus pormenores, a vida e os atos (e a obra literária ou a obra artística serão apenas atos, como quaisquer outros) de determinado personagem histórico, procurando compreender o jogo combinado dos fatores nas principais circunstâncias de sua existência" (BERGER. $O p$. cit. p. 27, 58). Os oito tipos caracterológicos são: Apaixonados, coléricos, sentimentais, nervosos, fleumáticos, sanguíneos, apáticos e amorfos. 
de forças excita as paixões dos leitores. Nessa influência pode haver algumas características correspondentes aos tipos de "homem" autor. Caso haja, cada tipo dirá também da qualidade de sua força vital subjacente à sua grande obra. Nesta, afrontamos e somos afrontados. Na grande obra encontra-se, por um lado, tanto a expressão como o acesso à vida (psicológica) do "homem" autor, pelo tipo de enfrentamento, autointerpretação e resolução dos conflitos existenciais. Por outro lado, apresenta tipos de pathos dominante, pelo "estilo" (d)e discurso (oral e escrito), influenciando, pela qualidade do jogo de forças resultantes, as paixões dos leitores. Se assim for, cada tipo "homem" autor traz consigo um tipo pathos (dominante). E a grande obra adquire tanto uma condição de "semiótica das paixões" como outra de "retórica das paixões". Ela é também o grande meio de comunicação daquilo que menos diretamente se pode comunicar - a vida (psicológica) mais suas forças (resultantes).

No que tange à nossa proposta, consideramos respondida a questão titular, "que diz a relação vida e obra?”. Sobre a noção de resolução, pelo diferencial da autointerpretação, expressa em uma grande obra, indicando qual postura do "homem" autor no enfrentamento dos seus conflitos existenciais, possibilitando-nos assim elaborar uma tipificação: o homem confissor, o homem contemplativo (goetheano), o homem agônico (nietzscheano), o homem auto-enganado, o homem (hipócrita) artista, o homem (hipócrita) platônico e o homem (hipócrita) burlador. Não sendo estáticos, os diferentes tipos "homem" autor encontram-se combinados no grande autor e expressos em suas ações (ato de criação das obras). Com o estudo dessas combinações, e da influência da grande obra nos leitores, a aproximação à vida concreta é real, pelos possíveis tipos existentes na obra de um grande homem.

\section{No se puede negar arte donde amenaçan yerros; ni hábito, donde reina la dificultad; ármase com reglas un sylogismo, fórjese com ellas un concepto. Mendiga dirección todo artificio, quanto más sutilezas del ingenio. Nace el hombre tan desnudo en alma como en el cuerpo de noticias y de plumas, pero la industria le desquita con vantajas. Arte de ingenio. Lorenço Gracian.}

(Salve nosso) Icaraí-CE; setembro, 2014.

\section{Referências}

ACCETTO. Torquato. Da dissimulação honesta. Tradução de Edmir Missio. São Paulo: Martins Fontes, 2001.

BENJAMIN, Walter. Documentos de cultura, documentos de barbárie: escritos escolhidos. Tradução de Celeste H. M., Ribeiro de Sousa... [et al.]. São Paulo: Cultrix: Editora da Universidade de São Paulo, 1986.

Ensaios reunidos: escritos sobre Goethe. Tradução de Mônica Krausz Bornebusch, 
Irene Aaron e Sidney Camargo. São Paulo: Duas Cidades; Ed. 34, 2009.

BERGER, Gaston. Tratado prático de análise do caráter. Tradução de Marcílio Teixeira Marinho. 2. ed. Rio de Janeiro: Agir, 1965.

BRUYÈRE, La. Caracteres ou costumes deste século. Tradução de Antonio Geraldo da Silva. São Paulo: Ed. Escala, [s.d.].

COSTA, Gustavo. Hipocrisia, moralidade, caráter. In: Nietzsche-Schopenhauer: Schopenhauer, Nietzsche e a antiguidade. Org.: Ruy de Carvalho, Gustavo Costa, Daniel Carvalho. Foaleza: EdUECE, 2012.

GIANNETTI, Eduardo. Auto-engano. São Paulo: Companhia das Letras, 1997.

GOLDSCHMIDT, Victor. A religião de Platão. 2 ed. Tradução de Ieda e Oswaldo Porchat Pereira. São Paulo: Difusão Européia do Livro, 1970.

HADOT, Pierre. O que é filosofia antiga?. Tradução de Dion Davi Macedo. São Paulo: Loyola, 1999.

KEHL, Maria Rita. Ressentimento. São Paulo: Casa do Psicólogo, 2014.

LOPES, Rogério. Ler Nietzsche contextualmente: a interpretação a partir das fontes. In: Nietzsche e a interpretação. Org.: Vânio Dutra de Azevedo, Ivo da Silva Júnior. Curitiba: CRV, 2012 - coedição: São Paulo: Humanitas, 2012.

LUKÁCS, Georg. A teoria do romance: um ensaio histórico-filosófico sobre as formas da grande épica. Tradução de José Marcos Mariani de Macedo. São Paulo: Duas Cidades; Ed. $34,2000$.

MELLO, Mário Vieira de. Nietzsche: o Sócrates de nossos tempos. São Paulo: EdUSP, 1993. NETO, Olimpio Pimenta. O que é filosofia?. In: Nietzsche e os gregos: arte, memória e educação> assim falou Nietzsche V. Org.: Charles Feitosa, Miguel Angel de Barrenechea, Paulo Pinheiro. Rio de Janeiro: DP\&A: Faperj: Unirio; Brasília, DF: Capes, 2006.

NIETZSCHE, F. W. Além do bem e do mal: prelúdio a uma filosofia do futuro. Tradução de Paulo César de Souza. São Paulo: Companhia das letras, 2005.

. Fragmentos finais. Tradução de Flávio R. Kothe. Brasília: Editora da Universidade de Brasília, 2002.

STEGMAIER, Werner. As linhas fundamentais do pensamento de Nietzsche. Orgs.: Jorge Luiz Viesenteiner, André Luiz Muniz Garcia. Petrópoles, RJ, Vozes, 2013. 